\title{
Productivity shocks and aggregate fluctuations in an estimated endogenous growth model with human capital*
}

\author{
Jim Malley \\ University of Glasgow and CESifo \\ Ulrich Woitek \\ University of Zurich and CESifo
}

August 22, 2011

\begin{abstract}
Employing an endogenous growth model with human capital, this paper explores how productivity shocks in the goods and human capital producing sectors contribute to explaining aggregate fluctuations in output, consumption, investment and hours. Given the importance of accounting for both the dynamics and the trends in the data not captured by the theoretical growth model, we introduce a vector error correction model (VECM) of the measurement errors and estimate the model's posterior density function using Bayesian methods. To contextualize our findings with those in the literature, we also assess whether the endogenous growth model or the standard real business cycle model better explains the observed variation in these aggregates. In addressing these issues we contribute to both the methods of analysis and the ongoing debate regarding the effects of innovations to productivity on macroeconomic activity.
\end{abstract}

Keywords: Endogenous growth, human capital, real business cycles, VECM measurement errors, Bayesian estimation JEL codes: C11, C52, E32

${ }^{*}$ We would like to thank Konstantinos Angelopoulos, Joe Byrne, David DeJong, Bernardo Xavier Fernandez, Peter Ireland, Apostolis Philippopoulos and Peter Rosenkranz for helpful comments and suggestions. Finally we would like to thank the Center for Economic Studies, University of Munich for financial support when undertaking part of this research. The usual disclaimer applies. 
We conclude that using the extra discipline of reproducing the trend productivity growth features of the data endogenously constitutes an important missing component from the real business cycle approach. (Jones et al., 2005, p. 805)

\section{Introduction}

Since the seminal work of Kydland and Prescott (1982) a significant amount of research has been undertaken to better understand the links between technology shocks and business cycles. Likewise the path-breaking research of Romer (1986) and Lucas (1988), stressing the roles of knowledge and human capital accumulation, has led to a large body of literature seeking to explain the determinants of endogenous growth. ${ }^{1}$ Quantifying the links between human capital and growth has already been well documented in the literature. For example, studies using reduced-form cross-sectional country or panel regressions unequivocally find a significant link between average years of schooling and growth (see e.g., Barro and Sala-i-Martin 2004, Barro 2001, 1991, de la Fuente and Domenech 2006). Other research, based on estimates of the steady-state relationship between growth and human capital, also conclude that human capital contributes significantly to growth (see, e.g. Mankiw et al. 1992, Benhabib and Spiegel 1994, Bils and Klenow 2000 and Temple 2001).

In stark contrast, there is a scarcity of research which estimates the deep parameters populating the equilibrium conditions of endogenous growth models. Perhaps the dearth of econometric evidence relating to estimates of these parameters can be explained by the limited availability of quality human capital data for this class of growth model and the previous technical difficulties associated with estimating dynamic stochastic general equilibrium (DSGE) models more generally. However, recent advances in econometric methods and applications go quite some way to mitigating both of these problems. $^{2}$ Moreover, using the state-space representation to evaluate the model's likelihood function via the Kalman Filter, would help to avoid problematic measurement issues relating to the human capital data by treating

\footnotetext{
${ }^{1}$ See the review papers by King and Rebelo (1999) and Rebelo (2005) for references on the importance of technology shocks in the real business cycle model. See also Barro and Sala-i-Martin (2004) and Aghion and Howitt (1998) for references on human capital based endogenous growth models.

${ }^{2}$ For example, DeJong et al. (2000a), DeJong and Ingram (2001), Ireland (2004), Ireland and Schuh (2008) and Malley and Woitek (2010) provide examples of estimated RBC or exogenous growth models using both classical and Bayesian methods. See also RugeMurcia (2007) for an extensive review of studies on the estimation of DSGE models.
} 
it as an unobservable state variable.

Another difficulty regarding the estimation of endogenous growth models relates to the vexed issue of how to account for trends or non-stationarity which may be present in the observed data but not in the theory. In contrast to business cycle models where exogenous trends are removed through a variety of deterministic and/or stochastic procedures, model-specific transformations are required to achieve stationarity in endogenous growth setups. Unfortunately, these transformations are generally not flexible enough to induce stationarity in the data required for estimation. To overcome this difficulty, we introduce a vector error correction model (VECM) of the measurement errors in the spirit of Ireland (2004) and Malley and Woitek (2010) who incorporate VAR and VARMA measurement errors respectively into the estimation of DSGE models. However, in contrast to these approaches, the VECM formulation is flexible enough not only to account for dynamic interactions but additionally trends or co-integrating relations in the observed data not captured by the theoretical economic model. To the best of our knowledge, the VECM model has not been utilized previously in this context. ${ }^{3}$ Hence our first intended contribution is methodological.

Using our modified framework, we further aim to shed new light on the ongoing debate regarding the effects of innovations to productivity on macroeconomic activity by estimating the posterior density functions of prototypical two-sector endogenous growth and one-sector exogenous growth models using U.S. quarterly data. ${ }^{4}$ Our estimated models then permit us to assess within sample fit using marginal likelihood comparisons and to evaluate the relative importance of total factor productivity (TFP) and human capital productivity $(\mathrm{HCP})$ in explaining aggregate fluctuations via impulse responses and forecast error variance decompositions (FEVDs).

We first find, when accounting for aggregate fluctuations in output, consumption, investment and hours, that the combined explanatory power of the TFP and HCP shocks in the human capital (HC) model is generally much larger than innovations to TFP in the RBC model. Second, the HC model significantly improves on the RBC model's ability to explain investment fluctuations, especially in the short-run. Third, while there is still ample room for improvement, the HC model does significantly better at explaining hours

\footnotetext{
${ }^{3}$ For a Bayesian treatment of VECM models, see, e.g. DeJong (1992), Bauwens and Lubrano (1996), Geweke (1996) and Kleibergen and van Dijk (1998).

${ }^{4}$ See Malley and Woitek (2010) for a selected literature review of this debate and for references to the literature on the Bayesian estimation of DSGE models starting with the simulation based methods pioneered by DeJong et al. (2000a,b). See also Ireland and Schuh (2008) and DeJong and Ingram (2001) for recent contributions employing estimated $\mathrm{RBC}$ models to examine the effects of disaggregated productivity shocks.
} 
variations than the RBC model. Finally, except for hours worked, TFP shocks in the $\mathrm{HC}$ model explain a relatively larger proportion of the cyclical fluctuations in these aggregates.

\section{Prototype endogenous growth model}

In this section, we solve for the optimal decisions of households and firms relying on the Lucas (1988) and Tamura (1991) setups. The engine of longterm growth in these models is human capital accumulation. The general equilibrium solution we derive consists of a system of dynamic relations, which jointly specify the paths of output, consumption, physical capital, human capital growth, and the fractions of time allocated to work, leisure and education. Since the Lucas and Tamura models are well known and effectively represent the industry standard for this class of endogenous growth model (see, e.g. Klenow and Rodríguez-Clare 2005 for a review), the main purpose of this section is to set out notation and variable definitions which will be used in the estimation and analysis which follows.

To facilitate the econometric estimation and comparability with the workhorse HC model, our deliberately minimal deviations from the Lucas and Tamura setups include: (i) non-zero depreciation rates for human and physical capital ${ }^{5}$ (ii) the change in human capital is positively related to human capital investment via a time-varying stochastic productivity term instead of a constant one; (iii) TFP is also time-varying and stochastic instead of being fixed; and (iv) labor supply is endogenous to facilitate comparisons with the RBC model. ${ }^{6}$

\subsection{Households}

The economy consists of a large number of identical households indexed by the subscript $h$ and identical firms indexed by the subscript $f$, where $h, f=1,2, \ldots, N_{t}$. The population size, $N_{t}$, evolves at a constant rate $n \geq 1$,

\footnotetext{
${ }^{5}$ Non-zero depreciation rates are not only necessary given that we will be taking the model to the data but also in light of the calibration findings by Jones et al. (2005) who state, "A second important finding stems from the fact that the depreciation rate on physical capital is larger than that on human capital. This single asymmetry imparts rich dynamics in the model's response to cyclical shocks".

${ }^{6}$ Given the well known difficulties relating to multiple equilibria when endogenous labor supply is incorporated into this class of model (see, e.g. Benhabib and Perli (1994)), to accommodate this extra household choice, we find more robust results in the estimation by excluding human capital externalities which appear in both the Lucas (1988) and Tamura (1991) models.
} 
such that $N_{t+1}=n N_{t}$, where $N_{0}$ is given. Each household's preferences are represented by the following time-separable utility function:

$$
E_{0} \sum_{t=0}^{\infty} \beta^{t} U\left(C_{t}^{h}, l_{t}^{h}\right)
$$

where $E_{0}$ is the conditional expectations operator; $C_{t}^{h}$ is consumption of household $h$ at time $t$; $l_{t}^{h}$ is leisure of household $h$ at time $t$; and $0<\beta<1$ is the discount rate. We use the $C R R A$ form for utility:

$$
U_{t}^{h}=\frac{\left[\left(C_{t}^{h}\right)^{\mu}\left(l_{t}^{h}\right)^{1-\mu}\right]^{1-\sigma}}{1-\sigma}
$$

where, $\sigma>1$ is the coefficient of relative risk aversion and $0<\mu<1$ is the weight given to consumption relative to leisure in utility.

Each household $h$ allocates income not consumed to investment, $I_{t}^{h}$, and receives interest income, $r_{t} K_{t}^{h}$, where $r_{t}$ is the return to holding capital and $K_{t}^{h}$ is the beginning-of-period capital stock. The household has one unit of time in each period $t$, which is apportioned between leisure, $l_{t}^{h}$, work, $u_{t}^{h}$, and education, $e_{t}^{h}$, such that:

$$
l_{t}^{h}+u_{t}^{h}+e_{t}^{h}=1
$$

A household with a stock of human capital at the beginning-of-period $t$, $H_{t}^{h}$ receives labor income, $w_{t} u_{t}^{h} H_{t}^{h}$, where $w_{t}$ is the wage rate and $u_{t}^{h} H_{t}^{h}$ is $h$ 's effective labor. ${ }^{7}$ Finally, each household receives dividends paid by firms, $\Pi_{t}^{h}$. Accordingly, the budget constraint of each household is:

$$
C_{t}^{h}+I_{t}^{h}=r_{t} K_{t}^{h}+w_{t} u_{t}^{h} H_{t}^{h}+\Pi_{t}^{h} .
$$

Each household's physical and human capital evolve according to:

$$
K_{t+1}^{h}=\left(1-\delta^{k}\right) K_{t}^{h}+I_{t}^{h}
$$

and

$$
H_{t+1}^{h}=\left(1-\delta^{h}\right) H_{t}^{h}+B_{t}\left(e_{t}^{h} H_{t}^{h}\right)
$$

where, $0 \leq \delta^{k}, \delta^{h} \leq 1$ are constant depreciation rates on private physical and human capital respectively. The term $B_{t}\left(e_{t}^{h} H_{t}^{h}\right)$ represents the quantity of "new" human capital created at time $t$, where $B_{t}$ denotes human capital productivity; and $\left(e_{t}^{h} H_{t}^{h}\right)$ is $h^{\prime} s$ effective human capital.

Households act competitively by taking $w_{t}$ and $r_{t}$ as given. Thus each household chooses $\left\{C_{t}^{h}, l_{t}^{h}, u_{t}^{h}, e_{t}^{h}, I_{t}^{h}, K_{t+1}^{h}, H_{t+1}^{h}\right\}_{t=0}^{\infty}$ to maximize (1) subject to (3)-(6) and initial conditions for the two capital stocks and the two productivity terms.

\footnotetext{
${ }^{7}$ Note that human capital, $H_{t} \equiv L_{t} H_{t}^{q}$, is the product of the quantity of workers $L_{t}$ and the quality or human capital per worker, $H_{t}^{q}$. Following Lucas (1988), it is assumed that $L_{t}$ and $H_{t}^{q}$ are perfect substitutes so that only $H_{t}$ matters for production.
} 


\section{$2.2 \quad$ Firm's problem}

To produce its homogenous final product, $Y_{t}^{f}$, each firm employs private physical capital, $K_{t}^{f}$, and effective labor, $u_{t}^{f} H_{t}^{f}$ using a Cobb-Douglas technology:

$$
Y_{t}^{f}=A_{t}\left(K_{t}^{f}\right)^{\alpha}\left(u_{t}^{f} H_{t}^{f}\right)^{1-\alpha}
$$

where $A_{t}$ represents the level of Hicks-neutral technology available to all firms, $0<\alpha<1$ and $(1-\alpha)$ are the efficiencies of private capital and effective labor respectively.

Firms act competitively by taking $w_{t}$ and $r_{t}$ as given. Accordingly, subject to (7), each firm chooses $K_{t}^{f}$ and $u_{t}^{f} H_{t}^{f}$ to maximize a series of static profit functions:

$$
\Pi_{t}^{f}=Y_{t}^{f}-r_{t} K_{t}^{f}-w_{t} u_{t}^{f} H_{t}^{f} .
$$

\subsection{Decentralized competitive equilibrium (DCE)}

The DCE is defined when (i) households and firms optimize, as above; (ii) all constraints are satisfied; and (iii) all markets clear. Given the $N_{t}$ identical households at time period $t$ and also $N_{t}$ identical firms, economy wide magnitudes are denoted $X_{t}=N_{t} X_{t}^{h}=N_{t} X_{t}^{f}$. Since human capital is the engine of long-run endogenous growth, we transform variables to make them stationary, i.e. we first define per capita quantities for any variable $X$ as $\bar{X}_{t} \equiv X_{t} / N_{t}$, where $X_{t} \equiv\left(Y_{t}, C_{t}, I_{t}, K_{t}, H_{t}\right)$ and then express these as shares of per capita human capital, e.g. $x_{t} \equiv \bar{X}_{t} / \bar{H}_{t}$. Finally, the gross human capital growth rate is defined as $\gamma_{t}^{h} \equiv \bar{H}_{t+1} / \bar{H}_{t}$. Using this notation and substituting out prices, $\left\{r_{t}, w_{t}\right\}_{t=0}^{\infty}$, we obtain the stationary DCE is summarized by a system of eight equations in the paths of the following eight variables: $\left(\gamma_{t}^{h}, y_{t}, c_{t}, u_{t}, e_{t}, k_{t+1}, \lambda_{t}^{a}, \lambda_{t}^{b}\right)$ given the exogenously set stationary AR processes whose motion is defined below. ${ }^{8}$

\subsection{Processes for productivity}

Given the above set-up, Hicks-neutral productivity, $A_{t}$, and human capital productivity, $B_{t}$, are stochastic. Following the usual practice in the RBC literature, ${ }^{9}$ we assume that each follows an $\mathrm{AR}(1)$ process:

$$
\begin{aligned}
& A_{t}=A^{\left(1-\rho^{a}\right)} A_{t-1}^{\rho^{a}} e^{\varepsilon_{t}^{a}} \\
& B_{t}=B^{\left(1-\rho^{b}\right)} B_{t-1}^{\rho^{b}} e^{\varepsilon_{t}^{b}}
\end{aligned}
$$

\footnotetext{
${ }^{8}$ See Appendix 6.1 for the detailed DCE.

${ }^{9}$ See, e.g. Kim and Lee (2007), DeJong and Ingram (2001) and Perli and Sakellaris (1998) for similar setups for the two productivity processes.
} 
where $A, B>0$ are constants, $0<\rho^{a}, \rho^{b}<1$ are the autoregressive parameters and $\varepsilon_{t}^{a}, \varepsilon_{t}^{b}$ are independent and identically distributed random shocks with zero means and variances equal to $\sigma_{a}^{2}$ and $\sigma_{b}^{2}$ respectively.

Innovations to TFP affect the efficiency of both capital and effective labor, whereas shocks to human capital productivity are purely labor augmenting. DeJong and Ingram $(2001,541-542)$ argue that $B_{t}$ can be thought of as "[...] an exogenous shock that shifts the efficiency with which hours are transformed into human capital. Examples of a negative shock are the creation of a new computer operating system that is more difficult to learn than the previous system and a decrease in funding for government-sponsored training programs. A positive shock could be a technological improvement in employee training methods".

\subsection{Model solution}

Following Klein (2000), we obtain the solution of the linearized stationary $\mathrm{DCE}^{10}$ in state space form:

$$
\begin{aligned}
\tilde{\mathbf{y}}_{t} & =\tilde{\mathbf{Z}}_{t} \boldsymbol{\delta}_{\boldsymbol{t}} ; \\
\boldsymbol{\delta}_{t+1} & =\tilde{\mathbf{T}} \boldsymbol{\delta}_{t}+\tilde{\boldsymbol{R}} \boldsymbol{\epsilon}_{t+1}
\end{aligned}
$$

where $\tilde{\mathbf{y}}_{t}=\left[\begin{array}{lll}\hat{y}_{t} & \hat{c}_{t} & \hat{u}_{t}\end{array}\right]^{\prime} ; \boldsymbol{\delta}_{t}=\left[\begin{array}{lll}\hat{k}_{t} & \hat{a}_{t} & \hat{b}_{t}\end{array}\right]^{\prime} ;$ for any variable $x_{t}, \hat{x}_{t}=\ln \left(x_{t} / x\right)$; $x$ is the model-consistent steady-state value of $x_{t} ; \hat{y}_{t}, \hat{c}_{t}$ and $\hat{u}_{t}$ are the control variables; $\hat{k}_{t}$ is the state variable; $\hat{a}_{t}$ and $\hat{b}_{t}$ are the two exogenous processes; $\tilde{\mathbf{Z}}$ and $\tilde{\mathbf{T}}$ are matrices containing various convolutions of the model's structural parameters; and $\tilde{\mathbf{R}}_{t}$ is a matrix of zeros and ones controlling two productivity shocks in the vector $\boldsymbol{\epsilon}_{t+1}$.

\section{Econometric Setup}

In the spirit of the hybrid estimation approach of Ireland (2004) and Malley and Woitek (2010), we next incorporate a $\operatorname{VAR}(1)$ representation of an $n$-dimensional VECM error block into the DSGE model given by equation (10). ${ }^{11}$ We calculate the model's likelihood function using the Kalman filter

\footnotetext{
${ }^{10}$ In other words, we take the first-order Taylor series expansion of the non-linear stationary DCE in eq. (21) and the exogenous processes in eq. (9) around the steady-state which we solve for numerically.

${ }^{11}$ Note that $n$ refers to the number of measurement equations. Also note that bolded $\boldsymbol{\alpha}, \boldsymbol{\beta}$ and $\boldsymbol{\mu}$ are vectors and as such should not be confused with the scalars $\alpha, \beta$ and $\mu$ used in the structural model.
} 
given that human capital, both types of technology shock, and the measurement errors will be treated as unobservables.

\subsection{VECM setup}

Since we have three measurement equations, we start with a VECM of order 1 to account for the other potential cointegrating relationship in the data not captured by the theoretical model. The VECM is given by:

$$
\Delta \boldsymbol{\mu}_{t+1}=\boldsymbol{\alpha} \boldsymbol{\beta}^{\prime} \boldsymbol{\mu}_{t}+\boldsymbol{\Gamma} \Delta \boldsymbol{\mu}_{t}+\boldsymbol{v}_{t+1} .
$$

In levels, this implies a VAR of order 2:

$$
\begin{aligned}
\boldsymbol{\mu}_{t+1} & =\left(\boldsymbol{\alpha} \boldsymbol{\beta}^{\prime}+\mathbf{I}_{n}\right) \boldsymbol{\mu}_{t}+\boldsymbol{\Gamma} \Delta \boldsymbol{\mu}_{t}+\boldsymbol{v}_{t+1}= \\
& =\left(\boldsymbol{\alpha} \boldsymbol{\beta}^{\prime}+\mathbf{I}_{n}+\boldsymbol{\Gamma}\right) \boldsymbol{\mu}_{t}-\boldsymbol{\Gamma} \boldsymbol{\mu}_{t-1}+\boldsymbol{v}_{t+1}
\end{aligned}
$$

The $\operatorname{VAR}(1)$ representation of (12) is:

$$
\left(\begin{array}{c}
\boldsymbol{\mu}_{t+1} \\
\boldsymbol{\mu}_{t}
\end{array}\right)=\underbrace{\left(\begin{array}{cc}
\mathbf{I}_{n}+\boldsymbol{\alpha} \boldsymbol{\beta}^{\prime}+\boldsymbol{\Gamma} & -\boldsymbol{\Gamma} \\
\mathbf{I}_{n} & \mathbf{0}
\end{array}\right)}_{\tilde{\mathbf{A}}}\left(\begin{array}{c}
\boldsymbol{\mu}_{t} \\
\boldsymbol{\mu}_{t-1}
\end{array}\right)+\left(\begin{array}{c}
\mathbf{I}_{n} \\
\mathbf{0}_{n \times n}
\end{array}\right) \boldsymbol{v}_{t+1} .
$$

Combining (10) and (13) yields the following state-space representation:

$$
\begin{aligned}
\tilde{\mathbf{y}}_{t} & =\left(\begin{array}{lll}
\tilde{\mathbf{Z}} & \mathbf{I}_{n} & \mathbf{0}_{n \times n}
\end{array}\right)\left(\begin{array}{c}
\boldsymbol{\delta}_{t} \\
\boldsymbol{\mu}_{t} \\
\boldsymbol{\mu}_{t-1}
\end{array}\right)=\mathbf{Z} \boldsymbol{\alpha}_{t} \\
\boldsymbol{\alpha}_{t+1} & =\left(\begin{array}{cc}
\tilde{\mathbf{T}} & \mathbf{0}_{n \times n} \\
\mathbf{0}_{2 n \times n} & \tilde{\mathbf{A}}
\end{array}\right) \boldsymbol{\alpha}_{t}+\left(\begin{array}{cc}
\tilde{\mathbf{R}} & \mathbf{0}_{n \times n} \\
\mathbf{0}_{n \times 2} & \mathbf{I}_{n} \\
\mathbf{0}_{n \times 2} & \mathbf{0}_{n \times n}
\end{array}\right)\left(\begin{array}{c}
\boldsymbol{\epsilon}_{t+1} \\
\boldsymbol{v}_{t+1}
\end{array}\right) \\
& =\mathbf{T} \boldsymbol{\alpha}_{t}+\mathbf{R} \boldsymbol{\eta}_{t+1}
\end{aligned}
$$

with

$$
\boldsymbol{\eta}_{t+1} \sim N(\mathbf{0}, \mathbf{Q}), \quad \mathbf{Q}=\left(\begin{array}{ccc}
\sigma_{a}^{2} & 0 & \mathbf{0}_{1 \times n} \\
0 & \sigma_{b}^{2} & \mathbf{0}_{1 \times n} \\
\mathbf{0}_{n \times 1} & \mathbf{0}_{n \times 1} & \boldsymbol{\Sigma}
\end{array}\right) .
$$

Note that the way we setup the matrices of the full state-space model implies that there is no interaction between the structural model and the measurement error component. 


\subsection{Estimation algorithm}

Using the data matrix, $\mathbf{Y}$, consisting of the vectors $\tilde{\mathbf{y}}_{t}, t=1 \ldots, T$, defined in (10), we estimate the vector of model hyper-parameters $\boldsymbol{\theta}$ using the tailored multiple-block Metropolis-Hastings (MH) algorithm proposed by Chib and Ramamurthy (2010), see also (Chib and Greenberg, 1994, 1995). ${ }^{12}$ This method separates parameters into different groups and updates them blockwise in an $\mathrm{MH}$ step, conditional on the remaining groups. Usually, parameter blocks are generated by searching for groups of correlated parameters, but this is difficult in a DSGE framework, since the parameters of the linear state space representation are non-linear combinations of the underlying parameters in $\boldsymbol{\theta}$. Instead, Chib and Ramamurthy (2010) randomize the formation of the parameter blocks since it helps to avoid poor a priori choices. This framework also allows parameter groupings to change, which is preferable if there are irregularities such as changes in the shapes of the posterior parameter distributions.

To generate these blocks, we permute the index of the parameters randomly. The first parameter initializes the first block. As in Chib and Ramamurthy (2010), the next parameter is included into this block with probability $\tau=0.8$, and starts a new block with probability $1-\tau$. Note that in simulation step $k$, the above algorithm generates $p_{k}$ blocks $\boldsymbol{\theta}_{k, 1}, \ldots, \boldsymbol{\theta}_{k, p_{k}}$. To find the maximum of the posterior with respect to block $j$, we keep all the other blocks constant and calculate

$$
\hat{\boldsymbol{\theta}}_{k, j}=\operatorname{argmax}\left(f\left(\mathbf{Y} \mid \boldsymbol{\theta}_{k, 1}, \ldots, \boldsymbol{\theta}_{k, j}, \ldots \boldsymbol{\theta}_{k, p_{k}}\right) \pi(\boldsymbol{\theta})\right)
$$

where $\pi(\boldsymbol{\theta})$ is the prior parameter distribution given in Table 1 below.

We use simulated annealing to calculate (16). ${ }^{13}$ The negative inverse Hessian $\mathbf{V}_{k, j}$ of the target posterior distribution is calculated at $\hat{\boldsymbol{\theta}}_{k, j}$. If it is not positive definite, a modified Cholesky decomposition (Gill and Murray, 1974) is applied to the negative Hessian to find the matrix $\mathbf{P}$, and $\mathbf{V}_{k, j}=$ $\left(\mathbf{P P}^{\prime}\right)^{-1}$. As in Chib and Ramamurthy (2010), the proposal density is a multivariate $t$-distribution with $\nu>2$ degrees of freedom. Drawing from this distribution, a candidate $\boldsymbol{\theta}_{k, j}^{\star}$ is generated, and accepted with probability

\footnotetext{
${ }^{12}$ Note that the value of the likelihood function in each MH-step is calculated using the Kalman filter (e.g. Harvey 1992).

${ }^{13}$ The algorithm is a generalization of the Metropolis algorithm (Metropolis et al., 1953) developed by Kirkpatrick et al. (1983) and Černý (1985). For an overview, see e.g. van Laarhoven and Aarts (1987) or Press et al. (1992, Section 10.9). We set the parameters for the algorithm as follows: scaling factor for parameter proposal: 0.02 ; cooling constant: 0.4; stage expansion factor: 8 ; initial temperature: 5 ; number of stages: 8 ; initial stage length: 4 .
} 


$$
\begin{aligned}
& p\left(\boldsymbol{\theta}_{k, j}^{\star}, \boldsymbol{\theta}_{k, j}\right)= \\
= & \min \left(\frac{f\left(\mathbf{Y} \mid \boldsymbol{\theta}_{k, 1}, \ldots, \boldsymbol{\theta}_{k, j}^{\star}, \ldots \boldsymbol{\theta}_{k, p_{k}}\right) g\left(\boldsymbol{\theta}_{k, j}^{\star}\right) t\left(\boldsymbol{\theta}_{k, j} \mid \hat{\boldsymbol{\theta}}_{k, j}, \mathbf{V}_{k, j}, \nu\right)}{f\left(\mathbf{Y} \mid \boldsymbol{\theta}_{k, 1}, \ldots, \boldsymbol{\theta}_{k, j}, \ldots \boldsymbol{\theta}_{k, p_{k}}\right) g\left(\boldsymbol{\theta}_{k, j}\right) t\left(\boldsymbol{\theta}_{k, j}^{\star} \mid \hat{\boldsymbol{\theta}}_{k, j}, \mathbf{V}_{k, j}, \nu\right)}, 1\right) .
\end{aligned}
$$

We employ the uniform distribution for all the elements of $(\boldsymbol{\theta})$ listed in Table 1 below. The priors we use for the supports of these distributions

Table 1: Priors for the parameter vector, $\boldsymbol{\theta}$

\begin{tabular}{lcc}
\hline \hline & Parameters & Restrictions \\
\hline & Structural & \\
capital's share & $\alpha$ & $(0.25,0.4)$ \\
discount rate & $\beta$ & $(0.97,0.99)$ \\
$K$ depreciation rate & $\delta^{k}$ & $(0.25 \times 0.05,0.25 \times 0.10)$ \\
$H$ depreciation rate & $\delta^{h}$ & $(0.25 \times 0.05,0.25 \times 0.10)$ \\
consumption/leisure weight & $\mu$ & $(0.25,0.45)$ \\
risk aversion parameter & $\sigma$ & $(1,3)$ \\
gross rate $N$ growth & $n$ & $\left(1,1.016^{0.25}\right)$
\end{tabular}

Productivity processes

$\mathrm{AR}(1)$ parameter in $A_{t}$ $\mathrm{AR}(1)$ parameter in $B_{t}$ $\rho^{a}$

$\rho^{b}$ $(0,<1)$

$A$ $(0,<1)$ constant term in $A_{t}$ constant term in $B_{t}$ s.d. $A$ shock s.d. $B$ shock

$B$

$\sigma^{a}$

$\sigma^{b}$ $(0.01,1)$

Measurement errors

VECM parameters variance-covariance matrix
$\Lambda$
$\Sigma$
$|E V|_{\max }<1$
$\Sigma$ is + semi-definite

solution

gross rate $H$ growth

Steady-state time shares unique $\gamma^{h}$ exitflag $=0$ (csolve.m)* expenditure shares $u ; e ; 1-u-e$ $\left(1.015^{0.25}, 1.04^{0.25}\right)$ $c / y ; i / y$ $(>0)$ ${ }^{*}$ csolve.m is the Matlab function by Chris Sims used to solve the non-linear system of equations comprising the model's steady-state, see ideas.repec.org/c/dge/qmrbcd/13.html. 
reflect non-sample information from: (i) the human capital model (including both parameter restrictions and non-negativity constraints); (ii) technical considerations regarding the existence of a unique steady-state equilibrium as well as the saddle path stability of the dynamic system; and (iii) the empirical plausibility of the historical value of long-run human growth. ${ }^{14}$ Finally, note that the VECM parameter restrictions referred to in Table 1 can be seen more clearly if we rewrite the VECM in equation (11) in VAR(1) representation:

$$
\left(\begin{array}{c}
\Delta \boldsymbol{\mu}_{t+1} \\
\boldsymbol{\beta}^{\prime} \boldsymbol{\mu}_{t+1}
\end{array}\right)=\underbrace{\left(\begin{array}{cc}
\boldsymbol{\Gamma} & \boldsymbol{\alpha} \\
\boldsymbol{\beta}^{\prime} \boldsymbol{\Gamma} & \boldsymbol{\beta}^{\prime} \boldsymbol{\alpha}+1
\end{array}\right)}_{\boldsymbol{\Lambda}}\left(\begin{array}{c}
\Delta \boldsymbol{\mu}_{t} \\
\boldsymbol{\beta}^{\prime} \boldsymbol{\mu}_{t}
\end{array}\right)+\left(\begin{array}{c}
\boldsymbol{v}_{t+1} \\
\boldsymbol{\beta}^{\prime} \boldsymbol{v}_{t+1}
\end{array}\right) .
$$

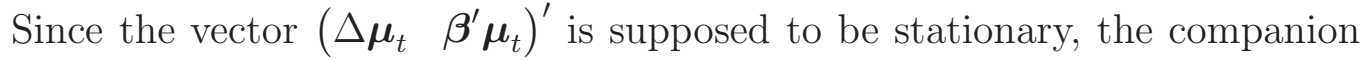
matrix $\Lambda$ is required to have eigenvalues less than one in absolute terms.

\subsection{Real business cycle model}

The exogenous growth RBC model can be viewed as a special case of similarly specified endogenous growth model. Thus to obtain the former from the HC model we: (i) replace endogenous human capital accumulation with exogenous labor augmenting technical process. For example, $\bar{H}_{t}=\left(\gamma^{h}\right)^{t}$ where $\gamma^{h}>1$, is typically used in RBC calibration and estimation studies; ${ }^{15}$ (ii) drop education time, $e_{t}$, from the time constraint; (iii) drop the two optimality conditions relating to education and human capital.

With respect to the parameter distributions to estimate as set out in Table 1 , these changes imply that $\delta^{h}=\sigma^{b}=\rho^{b}=B=0$. Finally note that when estimating the RBC model we apply the same priors reported in Table 1 for the remaining common parameters across models.

\section{Estimation results}

In this section we start by discussing the data, the required theory consistent de-trending transformations and the time-series properties of the de-trended data. We then present the first two moments of the estimated posterior parameter distributions, numerical standard errors and formal evidence relating

\footnotetext{
${ }^{14}$ Note that the more familiar annual figures (including the conversion factor to quarterly rates) are quoted for the depreciation rates and the gross population and human capital growth rates in Table 1.

${ }^{15}$ See, e.g. Ireland (2004) and Malley and Woitek (2010) for recent examples of the latter.
} 
to convergence for each parameter chain. We finally turn to an assessment of each model's ability to explain the observed data. To this end, we undertake within-sample fit comparisons, impulse response analysis and forecast error variance decompositions.

\subsection{Data and theory consistent de-trending}

The measured data used in the estimation includes quarterly per capita output, $\bar{Y}_{t}$, per capita consumption, $\bar{C}_{t}$, per capita capital stock, $\bar{K}_{t}$, and total economy hours, $u_{t}$, over the period $1964(1)$ to $2008(4) .{ }^{16}$ All data are seasonally adjusted at an annual rate except for population. ${ }^{17}$ Consistent with the model, output is defined as the sum of consumption plus investment.

To obtain theory consistent stationary variables in the estimation of the RBC and HC models, output and consumption must be written as shares of human capital per capita, $\bar{H}_{t}$, or in logs, $\ln y_{t}=\ln \bar{Y}_{t}-\ln \bar{H}_{t}$ and $\ln c_{t}=\ln \bar{C}_{t}$ $-\ln \bar{H}_{t}$. Normalizing by $\bar{H}_{t}$ is equivalent to removing a common exogenous log-linear trend in the RBC model and an endogenous local log-linear trend in the $\mathrm{HC}$ model. ${ }^{18}$ For example, in the RBC case,

$$
\begin{aligned}
\ln \left(\bar{H}_{t}\right) & =\omega t \\
\text { where } \omega & =\ln \left(\gamma^{h}\right)
\end{aligned}
$$

and in the $\mathrm{HC}$ case,

$$
\begin{aligned}
\ln \left(\bar{H}_{t}\right) & =\omega_{t} t \\
\text { where } \omega_{t} & =\frac{1}{t}\left[\sum_{j=1}^{t} \ln \left(\gamma_{j}^{h}\right)+\ln \left(\bar{H}_{0}\right)\right] .
\end{aligned}
$$

The difficulty with applying the above transformations for the estimation of the $\mathrm{HC}$ model is the general lack of quality human capital data. However,

\footnotetext{
${ }^{16}$ Real consumption (excluding durables) and investment (gross private domestic) are from the BEA and are in billions of chained $\$ 2005$. Hours (average weekly: total private industries) and population (civilian noninstitutional population) are from the BLS. Appendix 6.2 contains details on how the real capital stock is calculated from the BLS fixed asset tables.

${ }^{17}$ Note that the start date for the estimation is dictated by the availability of the total economy hours data. Although this data was previously available from 1948, the BLS switched from the SIC to the NAICS system in 2003. After this date, the relevant hours data is available from 1964 .

${ }^{18}$ Of course, since trends are exogenous in the RBC model, other deterministic and/or stochastic processes based on e.g. band-pass filters have been used in the literature to remove them. However, the well know difficulty associated with these filters is that overdifferencing leads to a loss of information, e.g. co-integrating relations and unconditional means of the data, which may be useful for identification.
} 
in light of the fact that US physical capital data (see BEA Fixed Asset Tables and Appendix 6.2) are far more reliable than human capital data, we can instead de-trend the $\mathrm{HC}$ model by $\bar{K}_{t}$ and treat $\bar{H}_{t}$, as an unobservable in the estimation. This requires that we re-derive the stationary DCE normalizing by $\bar{K}_{t}$ (see Appendix 6.3) and then resolve for the state space system in log deviations as in equation (18). Since, post estimation, we wish to analyze the properties of the endogenous growth model where human and not physical capital is the engine of growth, we retrieve the model solution in per $\bar{H}_{t}$ terms (see Appendix 6.4).

\subsection{Properties of de-trended data}

As discussed in the introduction, our motivation for adding VECM measurement errors is that the theory consistent de-trending required by the endogenous growth model will generally not lead to co-variance stationary series using actual data. To check this in the context of the current application, we first plot in Figure 1, the hours worked series, $u_{t}$, the de-trended data for the HC model, i.e. $\bar{C}_{t} / \bar{K}_{t}$ and $\bar{Y}_{t} / \bar{K}_{t}$ and the transformed data for the RBC model i.e. $\bar{C}_{t} /\left(\gamma^{h}\right)^{t}$ and $\bar{K}_{t} /\left(\gamma^{h}\right)^{t}{ }^{19}$ In Table 2 we then complement this information with a standard (classical) augmented Dicky-Fuller (ADF) test and a Bayesian unit root test based on Lubrano (1995) ${ }^{20}$

A visual inspection of Figure 1 suggests a clear trend in the hours data and in the per capital consumption and output data for the $\mathrm{HC}$ model. ${ }^{21}$ However, the plots are less conclusive for the de-trended RBC model data where both consumption and output appear to be mildly trending from 1985 .

\footnotetext{
${ }^{19}$ Note that the value for $\gamma^{h}$ is obtained by calculating the geometric average of the per capita gross growth rate of output over the estimation period, i.e. 1.0051 quarterly or 1.0206 annually.

${ }^{20}$ See, also Bauwens et al. (1999, Ch. 6) for a review of Bayesian unit root tests and the associated controversies.

${ }^{21}$ Note that hours worked is a stationary quantity in the theory given that it is part of the fixed time constraint. Hence, there are no model consistent transformations that would be appropriate for this series.
} 
Figure 1a: Hours data

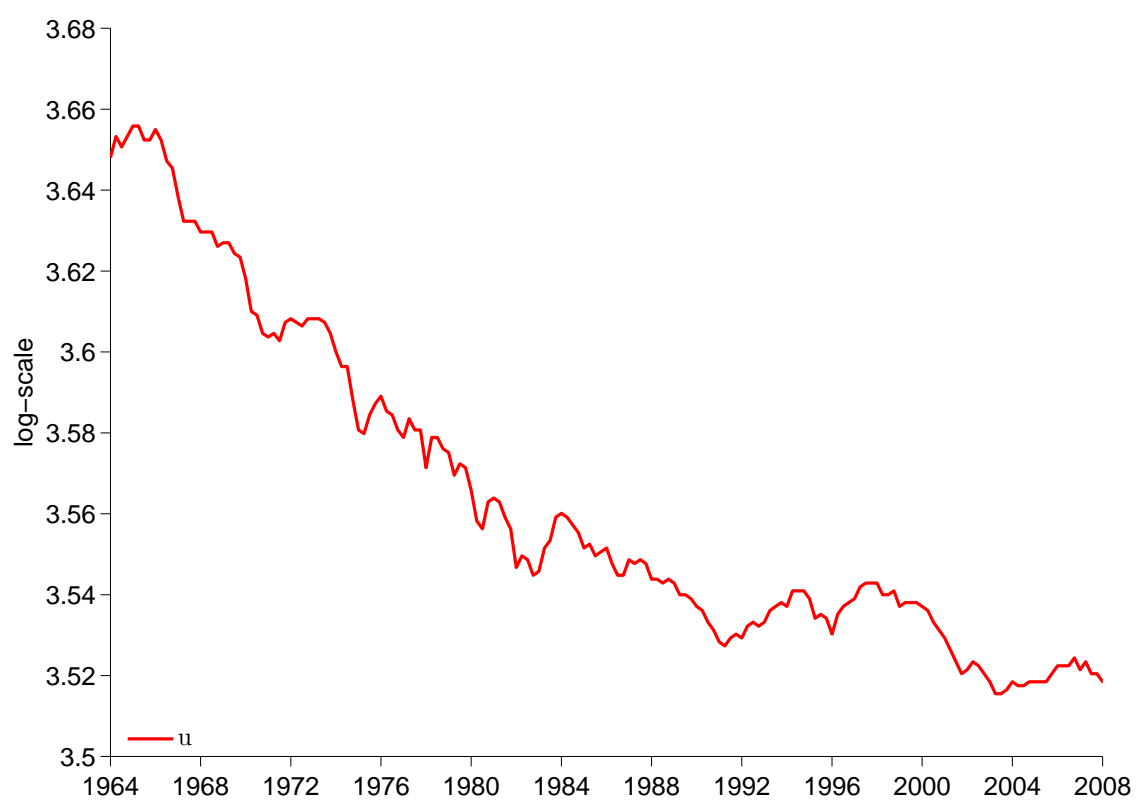

Figure 1b: HC data

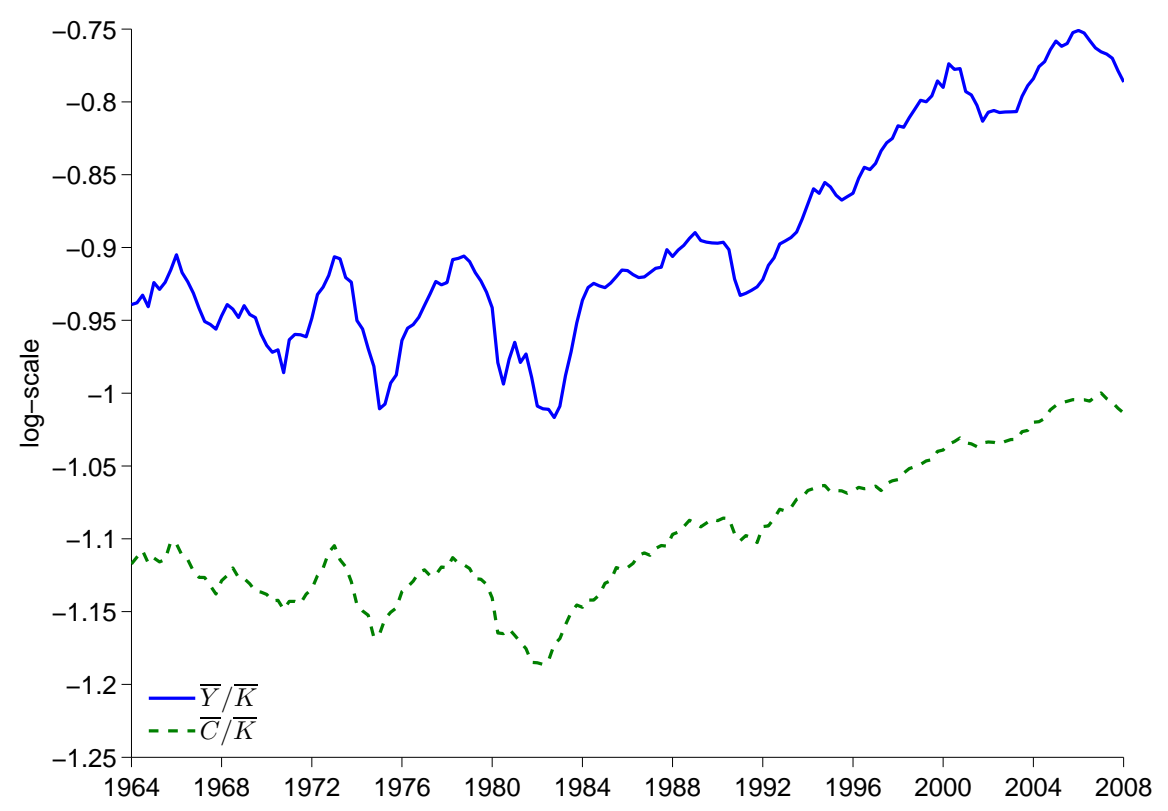


Figure 1c: RBC data

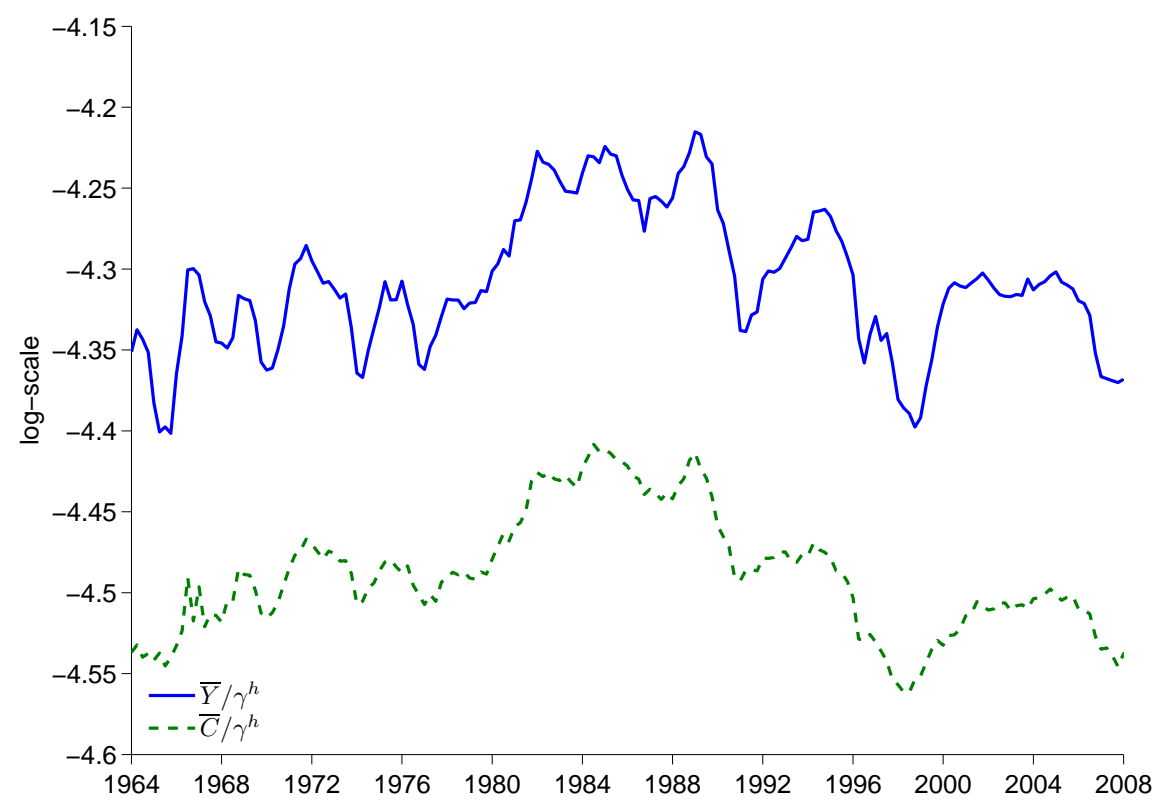

We now turn to more formal evidence regarding unit roots in the data. Following Lubrano (1995) the order of the $A R(p)$ model for any variable, $\widetilde{z}_{t}$,

$$
A(L)\left(\widetilde{z}_{t}-\widetilde{\mu}-\widetilde{\delta} t\right)=\widetilde{\epsilon}_{t} \text { where } \rho=1-A(1)
$$

with and without a deterministic trend is based on the Schwarz information criterion and is reported in the first column of Table 2. The ADF test statistic, $\tau$ and the tail probability from the posterior distribution of $\rho, \operatorname{Pr}(\rho \geq 1)$ are given in second and final columns respectively. The lag polynomial has a unit root if $A(1)=0$. Hence, the null hypothesis for both tests is that $\widetilde{z}_{t}$ contains a unit root or that $\rho=1$.

The findings in Table 2 below for both the classical and Bayesian tests suggest that unit roots are present for all series except for output in the RBC model. Thus, despite following theory-consistent stationary inducing transformations for consumption and output, neither the exogenous log-linear trend in the RBC model nor the endogenous local log-linear trend for the HC model is flexible enough to deliver uniformly stationary data for all variables. Of course, if a common-trend is employed, an alternative to the log-linear trend could be used to induce stationarity in both consumption and output 
for RBC model instead of the VECM procedure proposed here. ${ }^{22}$ However, in sharp contrast, no such flexibility is possible in the $\mathrm{HC}$ model since trend growth is endogenous.

\begin{tabular}{|c|c|c|c|}
\hline & $p$ & $\overline{\tau \tau}$ & 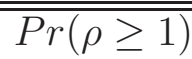 \\
\hline \multicolumn{4}{|c|}{ Constant } \\
\hline $\bar{Y}_{t} / \bar{K}_{t}$ & 2 & -1.43 & 0.308 \\
\hline $\bar{C}_{t} / \bar{K}_{t}$ & 3 & -1.25 & 0.088 \\
\hline $\bar{Y}_{t} /\left(\gamma^{h}\right)^{t}$ & 2 & $-3.30^{\star}$ & $0.005^{\star}$ \\
\hline $\bar{C}_{t} /\left(\gamma^{h}\right)^{t}$ & 2 & -2.11 & 0.166 \\
\hline$u_{t}$ & 1 & -2.14 & 0.185 \\
\hline \multicolumn{4}{|c|}{ Constant \& Trend } \\
\hline $\bar{Y}_{t} / \bar{K}_{t}$ & 2 & -2.86 & 0.132 \\
\hline $\bar{C}_{t} / \bar{K}_{t}$ & 3 & -2.85 & 0.999 \\
\hline $\bar{Y}_{t} /\left(\gamma^{h}\right)^{t}$ & 2 & $-3.27^{\star}$ & $0.021^{\star}$ \\
\hline $\bar{C}_{t} /\left(\gamma^{h}\right)^{t}$ & 2 & -2.34 & 0.425 \\
\hline$u_{t}$ & 1 & -2.08 & 0.443 \\
\hline
\end{tabular}

\subsection{Estimated parameter distributions}

Table 3 below summarizes the estimated parameter distributions by reporting their means and standard deviations along with a measure of estimation accuracy based on numerical standard errors, NSE, (Geweke, 1992). In addition, we calculate Geweke's $\chi^{2}$-test which, for each parameter chain, compares the mean of the first 20 per cent of the sample with the last 50 per cent. $^{23}$

Before discussing the detailed estimation results, it is first useful examine some aggregate evidence relating to the posterior likelihood functions of the $\mathrm{HC}$ and RBC models. These are displayed in Figure 2 for a total of 10,000 simulations and clearly suggest that the likelihood functions have converged to their respective maxima. It also appears from respective heights that the

\footnotetext{
${ }^{22}$ Note that, the trend in hours would still need to be removed in this case.

${ }^{23}$ The figures reported in Table 3 are based on a 15 per cent taper for the periodogram window underlying the calculation of NSE. To calculate this statistics, we use the programs coda.m and apm.m provided by James LeSage in his econometrics toolbox (wWw.spatial-econometrics.com).
} 
$\mathrm{HC}$ model provides a much better overall fit to the data. We examine this point more formally below.

Figure 2: Posterior likelihood functions

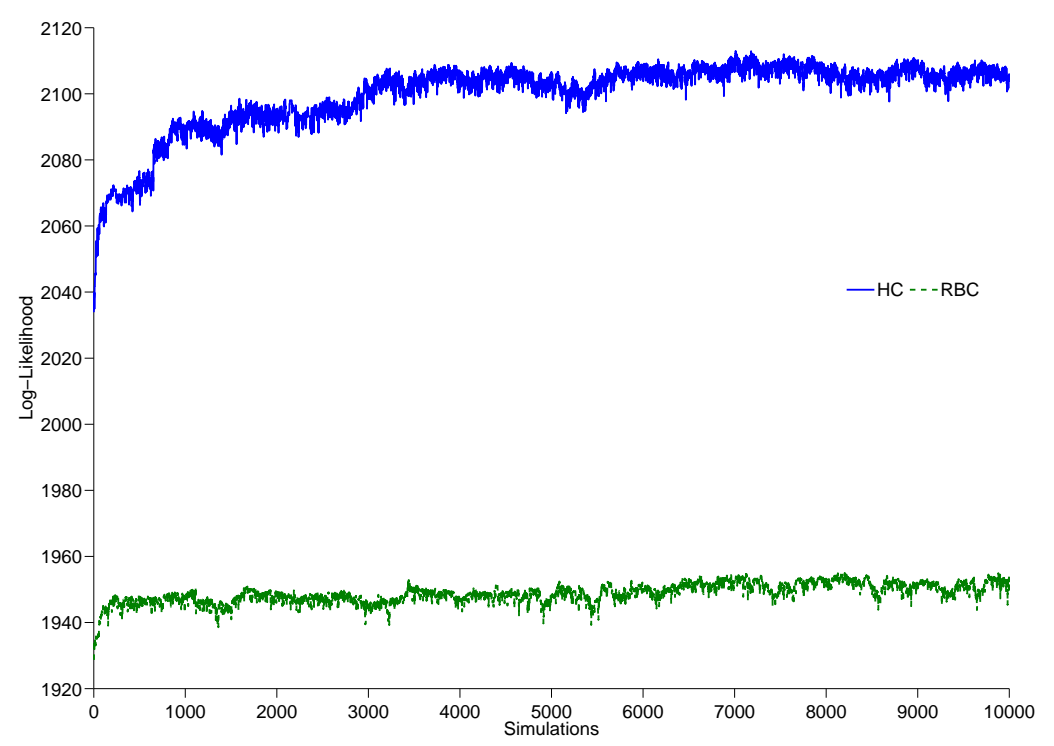

Starting with the structural parameters in Table 3 below, there are no surprises regarding the sizes of the means given our priors regarding the supports for the various distributions. However, it is noteworthy, consistent with the research of Jorgenson and Fraumeni (1989) and Jones et al. (2005), that $\delta_{k}>\delta_{h}$. The biggest differences across models appear to be that in the HC model, the discount rate, $\beta$, and the weight attached to consumption in utility, $\mu$, are both lower than in the RBC model. The latter in conjunction with relative risk aversion parameter, $\sigma$, imply that the intertemporal elasticity of consumption, $\frac{1}{\mu(1-\sigma)-1}$, and leisure, $\frac{1}{(1-\mu)(1-\sigma)-1}$, are -0.556 and -0.487 for the RBC model and -0.669 and -0.418 for the $\mathrm{HC}$ model respectively. Otherwise, the remaining estimated structural parameters for both the $\mathrm{HC}$ and $\mathrm{RBC}$ models are of similar orders of magnitude. To more fully understand the quantitative implications of all these differences, we examine the impulse responses of both models below. 
Table 3: Posterior Distributions of Parameters, $\boldsymbol{\theta}$

Structural Parameters

\begin{tabular}{|c|c|c|c|c|c|c|c|c|}
\hline \multirow[b]{2}{*}{$\psi_{j}$} & \multicolumn{4}{|c|}{ HC Model } & \multicolumn{4}{|c|}{ RBC Model } \\
\hline & mean & s.d. & $\frac{N S E}{\mid \theta_{i}}$ & $\chi^{2}$ & mean & s.d & $\frac{N S E}{\mid \theta_{j}}$ & $\chi^{2}$ \\
\hline$\alpha$ & 0.39403 & 0.00604 & 0.00089 & 0.20223 & 0.36015 & 0.03694 & 0.00258 & 0.14713 \\
\hline$A$ & 0.60027 & 0.27182 & 0.05163 & 0.52254 & 0.81734 & 0.15205 & 0.01050 & 0.52273 \\
\hline$B$ & 0.13484 & 0.01078 & 0.00093 & 0.52329 & na & na & na & na \\
\hline$\beta$ & 0.97668 & 0.00150 & 0.00020 & 0.70217 & 0.99366 & 0.00501 & 0.00028 & 0.21908 \\
\hline$\delta_{k}$ & 0.03347 & 0.00375 & 0.00117 & 0.11431 & 0.03093 & 0.00517 & 0.00025 & 0.20724 \\
\hline$\delta_{h}$ & 0.01082 & 0.00080 & 0.00062 & 0.61194 & na & na & na & na \\
\hline$n$ & 1.00072 & 0.00065 & 0.00010 & 0.17347 & 1.00247 & 0.00125 & 0.00007 & 0.42546 \\
\hline$\mu$ & 0.26216 & 0.01179 & 0.00040 & 0.20274 & 0.43110 & 0.01905 & 0.00146 & 0.51146 \\
\hline \multirow[t]{3}{*}{$\sigma$} & 2.89046 & 0.11045 & 0.00590 & 0.06336 & 2.85455 & 0.14083 & 0.00987 & 0.68824 \\
\hline & \multicolumn{7}{|c|}{ Productivity Processes } & 0.00000 \\
\hline & \multicolumn{4}{|c|}{ HC Model } & \multicolumn{3}{|c|}{ RBC Model } & 0.00000 \\
\hline$\psi_{j}$ & mean & s.d. & $\frac{N S E}{\mid \theta_{j}}$ & $\chi^{2}$ & mean & s.d. & $\frac{N S E}{\mid \theta_{j}}$ & $\chi^{2}$ \\
\hline$\rho_{a}$ & 0.99154 & 0.00191 & 0.00002 & 0.10282 & 0.99713 & 0.00237 & 0.00020 & 0.74209 \\
\hline$\rho_{b}$ & 0.99027 & 0.00245 & 0.00003 & 0.36348 & na & na & na & na \\
\hline$\sigma_{a}$ & 0.00408 & 0.00005 & 0.00388 & 0.13849 & 0.00476 & 0.00046 & 0.00010 & 0.45352 \\
\hline \multirow[t]{3}{*}{$\sigma_{b}$} & 0.00427 & 0.00014 & 0.00909 & 0.88048 & na & na & na & na \\
\hline & \multicolumn{7}{|c|}{ Summary: VECM Measurement Errors } & 0.00000 \\
\hline & \multicolumn{4}{|c|}{ HC Model } & \multicolumn{3}{|c|}{ RBC Model } & 0.00000 \\
\hline$\psi_{j}$ & mean & s.d. & $\frac{N S E}{\mid \theta_{j}}$ & $\chi^{2}$ & mean & s.d. & $\frac{N S E}{\mid \theta_{j}}$ & $\chi^{2}$ \\
\hline$\overline{\Lambda_{|E|}}$ & 0.83391 & 0.03150 & 0.00411 & 0.21524 & 0.79840 & 0.03609 & 0.00397 & 0.99055 \\
\hline $\operatorname{Tr}(2$ & 0.00004 & 0.00000 & 0.01621 & 0.53879 & 0.00012 & 0.00001 & $3.48 \mathrm{E}-6$ & 0.66724 \\
\hline
\end{tabular}

Turning to the two productivity processes, the high values for $\rho_{a}$ and $\rho_{b}$ suggest that innovations to technology are highly persistent. This echoes the results reported in Ireland (2001) and Malley and Woitek (2010). ${ }^{24}$ The mean value of the variance of the Hicks-neutral technology process, $\sigma_{a}$, for both the $\mathrm{RBC}$ and $\mathrm{HC}$ models is consistent with other estimates in the literature at about half-a-percent. Also note that the estimate of $\sigma_{b}$, in the $\mathrm{HC}$ is roughly of the same magnitude and while greater than $\sigma_{a}$, in the $\mathrm{HC}$ model, it is less than $\sigma_{a}$, in the RBC model. Again, the fuller implications of these estimates will be become apparent below in the context of the FEVDs.

To save space, the final block of parameters reported in Table 3, consisting

\footnotetext{
${ }^{24}$ Also note that the above authors find that the data prefer the trend-stationary to difference-stationary technology in the standard RBC model.
} 
of the maximum absolute eigenvalue of the companion matrix, $\boldsymbol{\Lambda}$, and the trace of variance-covariance matrix, $\boldsymbol{\Sigma}$, summarizes information relating to the 20 parameters in the VECM block. These include 9 from the VAR coefficient matrix; 6 from the variance-covariance matrix; 3 from the errorcorrection or factor loading vector; and 2 from the co-integrating vector.

Turning to the degree of uncertainty associated with all of the estimates in the Table 3, we find via the standard deviations, that all the parameter distributions are quite concentrated. Moreover, examination of the numerical standard errors as a share of the absolute value of the means of the posteriors reveals that our estimates are very precisely estimated. Finally the Geweke $\chi^{2}$-test shows that all parameter chains have converged.

\subsection{Within sample fit}

To more formally assess the difference in posterior likelihoods presented in Figure 2, we next calculate the Bayes factor based on marginal likelihoods obtained from the simulated parameter realizations. For example, if we let $M_{H C}$ denote the $\mathrm{HC}$ model, and $M_{R B C}$ the RBC model. The Bayes factor for comparing the models is given by the ratio of the two marginal likelihoods ${ }^{25}$ for $M_{H C}$ and $M_{R B C}$,

$$
B F_{H C, R B C}=\frac{p\left(\mathbf{Y} \mid M_{H C}\right)}{p\left(\mathbf{Y} \mid M_{R B C}\right)}
$$

The log-difference between the marginal likelihoods of the $\mathrm{HC}$ and $\mathrm{RBC}$ models is 105.45 suggesting that the former provides a far better within sample fit to the data (see, e.g. Kass and Raftery, 1995, p. 777).

\subsection{Impulse response functions}

To obtain a quantitative impression of how model outcomes are affected by the parameter estimates in Table 3 we next examine the impulse responses (IRFs) of the two models to a temporary 1-percent increase in TFP. The IRFs in Figure 3 below are reported as percent differences from the steady-state for 60 quarters and include $90 \%$ highest posterior density intervals.

The plots for the RBC model (dotted line) show the expected results. That is, on impact, the marginal products of capital and labor increase. The IRFs show that as a result agents work and invest more leading to greater output. Consumption also increases but by less than the increase in

\footnotetext{
${ }^{25}$ To calculate the marginal likelihoods, we follow the harmonic mean approach of Newton and Raftery (1994).
} 
output due to consumption smoothing. Since the TFP shock is temporary, all variables eventually return to their respective steady-states at a speed which depends on $\delta_{k}, \delta_{h}$, and the size of $\rho^{a}$ in the TFP processes. Consistent with the estimated values of $\rho^{a}$, Figure 1 illustrates that TFP is an extremely persistent trend stationary process in both models.

The HC model (solid line) responds qualitatively in a similar manner as the RBC model for output and its components. However, the responses in the HC model are relatively higher for around five years. This is because human capital growth and its per capital level have risen due to the increase in time allocated to education. The increase in education time occurs since, given the increased return to working, households can afford to substitute work with education time. Households also find it optimal to substitute leisure for education since the positive effects of increased consumption on utility arising from higher human capital growth appear to outweigh the negative effects of less leisure. Note that despite the fall in hours worked, $\widehat{u}_{t}$, effective labor, $\widehat{u}_{t}+\widehat{H}_{t}$, increases and encourages greater capital accumulation which complements effective labor in production. In sharp contrast, in the RBC model, the increase in hours worked, due to higher returns, is absorbed by a fall in leisure. We will see in the FEVDs below that this extra use of time in the $\mathrm{HC}$ model has important implications for its ability to explain aggregate hours.

Examination of the $90 \%$ highest posterior density (HPD) intervals indicate that, except for output and investment after five years and consumption for all time horizons, the distributions of the impulse response functions do not generally overlap. Also except for output and consumption, at 10 years and above, the distributions appear to be reasonably concentrated.

Finally it is worth noting that a clear model implication of the estimated endogenous growth $\mathrm{HC}$ model is that fluctuations in education time and output deviations are procyclical. This is in contrast to the findings of exogenous growth RBC models with human capital, see, e.g. DeJong and Ingram (2001) and Perli and Sakellaris (1998), who find a countercyclical link due to the increased opportunity cost of not working when TFP increases.

Reference to the stylized facts regarding this relationship appear to be inconclusive however. For example DeJong and Ingram (2001), using college enrollment data from the October supplement of the Current Population Survey state that the data "... indicate a negative relationship between the growth rates of output and college enrollments in the U.S. The raw correlation between these series is -0.31 over the period $1970-1996$. Moreover, Dellas and Sakellaris (1996) found college enrollments to be countercyclical using a probit analysis that controlled for a wide range of factors." 
Figure 3: Impulse responses
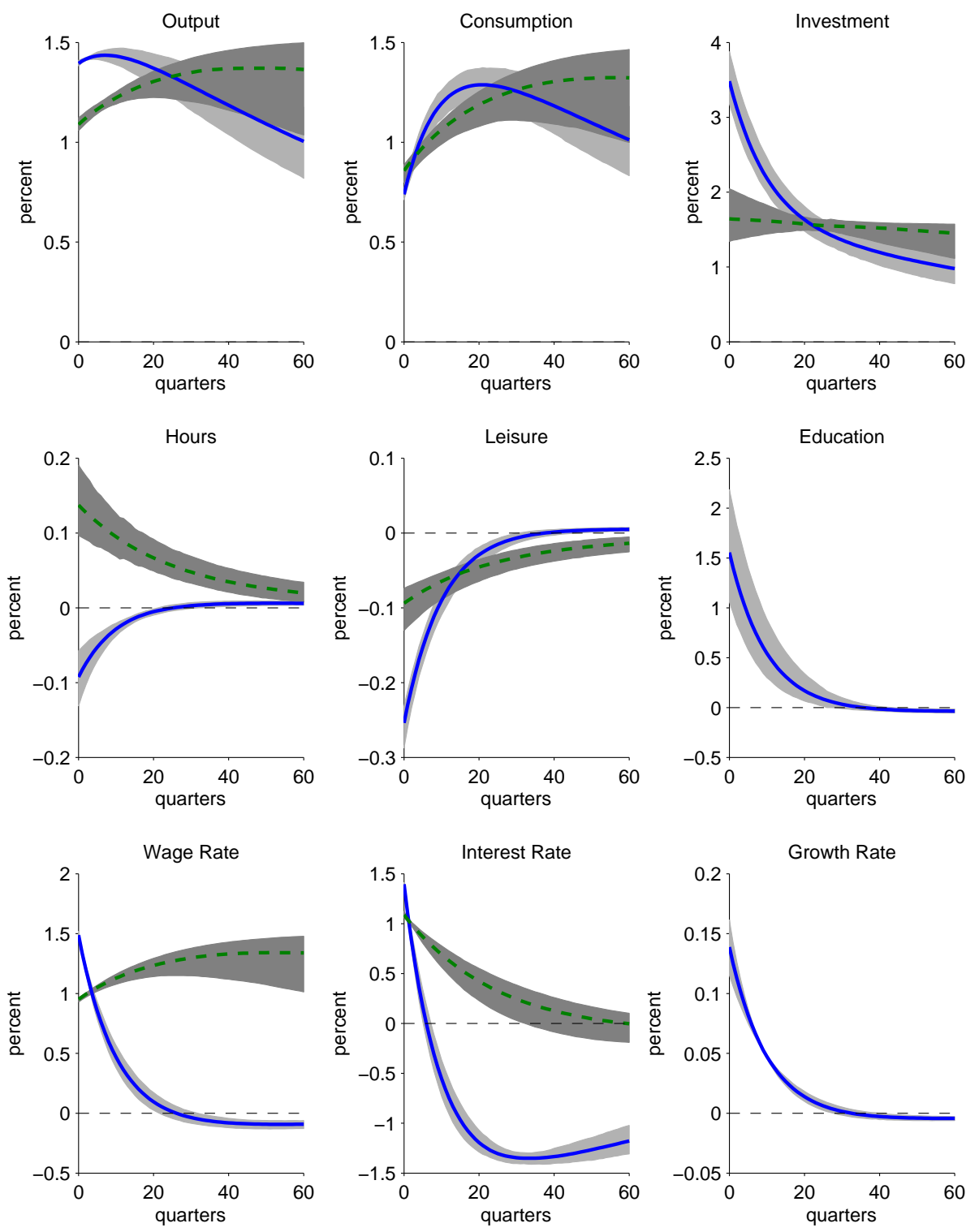

$\longrightarrow \mathrm{HC}=--\mathrm{RBC}$ 
In contrast the simple correlations in Table 4 below provide a somewhat different picture and suggest a procyclical link between fluctuations in college enrollments and output. ${ }^{26}$ Besides the different time periods employed in the studies cited above and in Table 4, the correlations might also differ due to the different survey coverage employed by the US Census Bureau. For example, the Current Population Survey reports college enrollment of students 14 years old and over, whereas the US National Center for Education Statistics (Table 4), reports college enrollment for persons 16 to 24 who graduated from high school in the preceding 12 months. ${ }^{27}$ In any event, college enrollments, while the best available measure, is not broad enough to capture what is intended by education time in both endogenous and exogenous growth human capital models. For example, this measure does not capture non-college education post high school nor on the job training.

Table 4: Trend and cyclical college enrollment $(C E)$ -

\begin{tabular}{lc}
\multicolumn{2}{c}{ output $(Y)$ correlations $(1960-2008)$} \\
\hline \hline$\rho(C E, Y)$ & 0.7934 \\
$\rho\left(C E_{\text {lin }}, Y_{\text {lin }}\right)$ & 0.6023 \\
$\rho\left(C E_{\text {quad }}, Y_{\text {quad }}\right)$ & 0.5315 \\
$\rho\left(C E_{\Delta}, Y_{\Delta}\right)$ & 0.1501 \\
$\rho\left(C E_{h p}, Y_{h p}\right)$ & 0.1505 \\
\hline
\end{tabular}

Source CE data: US Digest of Education Statistics.

\subsection{Forecast error variance decompositions}

We next turn to an assessment of the HC and RBC models' ability to explain the observed variation in the measured variables (i.e. output, consumption, investment and hours). To this end, we undertake FEVDs which allows us to split the $k$-step-ahead forecast error variances of the measured variables into the portions explained by shocks to technology and to the measurement errors. ${ }^{28}$ The former includes the common $A$ shock for both models and the $B$ shock for the $\mathrm{HC}$ model. Innovations to the error system in contrast, pick up the combined effects of shocks, not present in the structural model(s) ${ }^{29}$

\footnotetext{
${ }^{26}$ Note that the data used in Table 4 are logged prior to detrending with deterministic (i.e. linear and quadratic) and stochastic (first-difference and Hodrick-Prescott) procedures.

${ }^{27}$ These data can also be found in US Census Bureau 2011, Statistical Abstract, Table 272.

${ }^{28}$ Note that the FEVDs are posterior distributions based on the draws we retain from each of the chains.

${ }^{29}$ Recall that these three errors include one for each measured variable, i.e. output, consumption and hours. A fourth is not required for investment since it follows residually
} 
Table 5 reports, for the $\mathrm{HC}$ and $\mathrm{RBC}$ models respectively, the median percent of the total forecast error variance (FEV) for each measured variable explained by innovations to neutral, $A$, and labor augmenting, $B$, technical change along with the first and third quartile. These results first suggest that when accounting for aggregate fluctuations, the combined explanatory power of the TFP and HCP shocks in the HC model is generally much larger than innovations to TFP in the RBC model for all variables considered. This especially holds over the business cycle horizon, i.e. 3-5 years. The only case where TFP in the RBC model marginally dominates the combined productivity shocks in the $\mathrm{HC}$ is for investment at infinity.

The results also suggest that the HC model significantly improves on the RBC model's ability to explain investment fluctuations for at least 5-years, e.g. compare the median value of the combined productivity shocks in the HC model with the $A$ shock in the RBC model. This finding is consistent with the much more elastic response of investment in the $\mathrm{HC}$ model depicted in the impulse responses of Figure 3. As explained above, this is driven by the endogenous increase in education time and hence growth in this setup.

Table 5 further indicates that while there is still ample room for improvement, the HC model does significantly better at explaining hours variations than the RBC model throughout the forecast horizon. However, in both models, the explanatory power of the technology shocks monotonically declines as the forecast horizon increases. Comparing the effects of $A$ versus $B$ shocks in the $\mathrm{HC}$ model, the results further suggest that with the exception of hours worked, TFP shocks explain a relatively larger proportion of the cyclical fluctuations in the measured variables. Also, compared to output and consumption, we can also see that $B$ shocks are relatively more important in explaining the FEV of investment.

Further evidence from the 3-quartile range suggests that the distributions of the FEVDs are generally concentrated and quite distinct. Regarding the latter, comparing the distributions of $A+B$ from the $\mathrm{HC}$ model with $A$ from the $\mathrm{RBC}$ model indicates that strong overlap in distributions only occurs for: (i) output at 5-years and above; (ii) consumption at 3-years and above; and (iii) investment at 10 -years and above. No overlap is present at any forecast horizon for hours.

from output and consumption. To save space, we do not present these but the FEDVs associated with each measurement error are available on request. Further note that since the FEVDs are normalised, the contribution of the error block as a whole can be easily implied by subtracting the contribution of technology shock(s) from unity. 
Table 5: Forecast Error Variance Decomposition: Quantiles

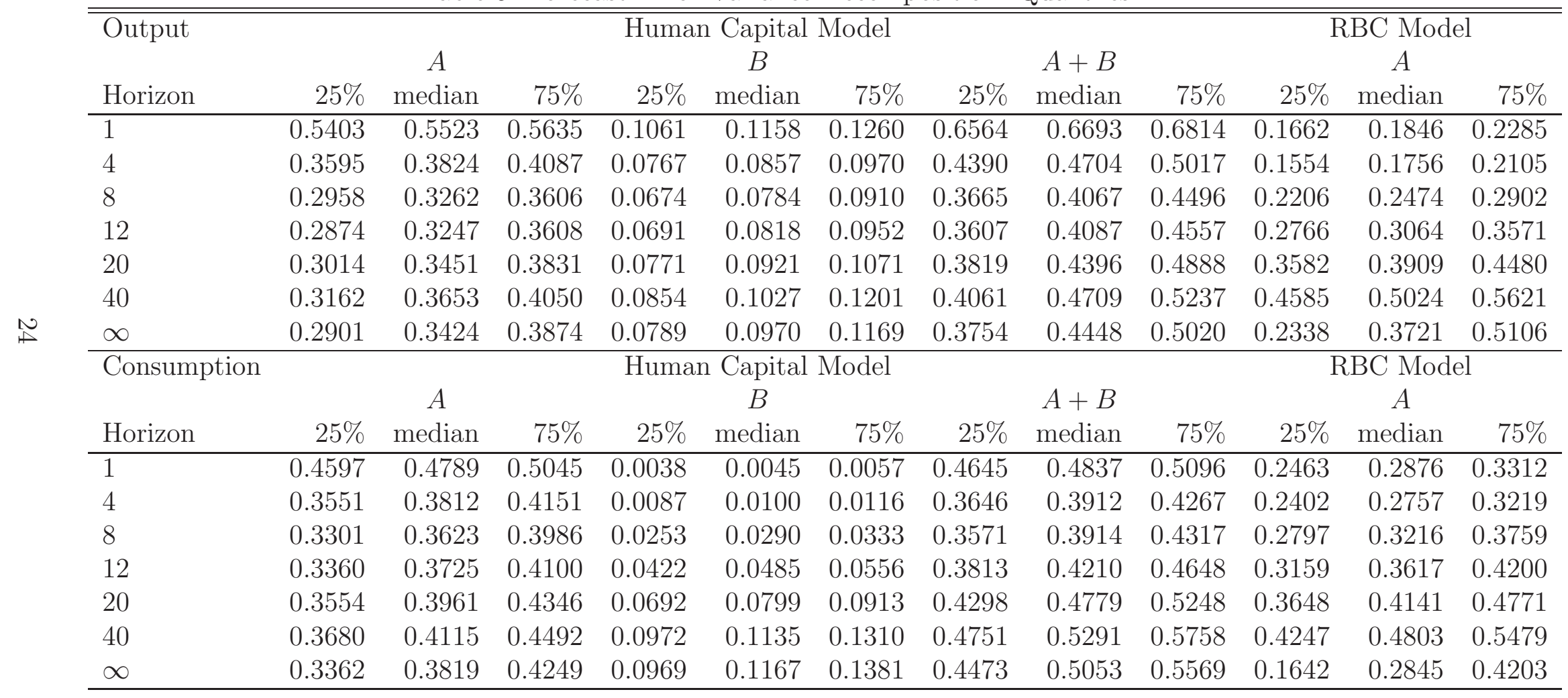


Table 5: Forecast Error Variance Decomposition: Quantiles

\begin{tabular}{|c|c|c|c|c|c|c|c|c|c|c|c|c|}
\hline \multirow{3}{*}{$\begin{array}{l}\text { Investment } \\
\text { Horizon }\end{array}$} & \multicolumn{9}{|c|}{ Human Capital Model } & \multicolumn{3}{|c|}{ RBC Model } \\
\hline & \multicolumn{3}{|c|}{$A$} & \multicolumn{3}{|c|}{ B } & \multicolumn{3}{|c|}{$A+B$} & \multicolumn{3}{|c|}{ A } \\
\hline & $\begin{array}{r}25 \% \\
03399\end{array}$ & $\frac{\text { median }}{03552}$ & $\begin{array}{r}75 \% \\
03695\end{array}$ & $\begin{array}{r}25 \% \\
02355\end{array}$ & $\frac{\text { median }}{02538}$ & $\begin{array}{r}75 \% \\
02732\end{array}$ & $\frac{25 \%}{5889}$ & & $\frac{75 \%}{6318}$ & $\begin{array}{r}25 \% \\
00646\end{array}$ & $\frac{\mathrm{an}}{76}$ & $\frac{75 \%}{5975}$ \\
\hline 4 & 02682 & 0.2834 & 03006 & 0.1718 & $\begin{array}{l}0.2538 \\
0.1808\end{array}$ & 0.2132 & 0.5889 & 0.0098 & 0.0318 & 0.0040 & 0.0160 & 0.0975 \\
\hline $\begin{array}{l}4 \\
8\end{array}$ & 0.207 & & & 0.1718 & 0.1898 & & 0.4473 & 0.4756 & 0.5098 & 0.0670 & 0.0802 & 0.0986 \\
\hline 8 & 0.2197 & 0.2420 & 0.2689 & 0.1303 & 0.1514 & 0.1765 & 0.3535 & 0.3955 & 0.4448 & 0.1055 & 0.1250 & 0.1529 \\
\hline 12 & 0.2076 & 0.2375 & 0.2692 & 0.1160 & 0.1393 & 0.1653 & 0.3277 & 0.3788 & 0.4343 & 0.1380 & 0.1622 & 0.1968 \\
\hline 20 & 0.2096 & 0.2482 & 0.2837 & 0.1062 & 0.1312 & 0.1574 & 0.3197 & 0.3812 & 0.4429 & 0.1944 & 0.2262 & 0.2721 \\
\hline 40 & 0.2129 & 0.2614 & 0.3010 & 0.0928 & 0.1170 & 0.1428 & 0.3074 & 0.3802 & 0.4448 & 0.2851 & 0.3326 & 0.3880 \\
\hline$\infty$ & 0.1921 & 0.2478 & 0.2938 & 0.0731 & 0.0953 & 0.1191 & 0.2677 & 0.3455 & 0.4133 & 0.2447 & 0.3779 & 0.4895 \\
\hline \multirow[t]{2}{*}{ Hours } & \multicolumn{9}{|c|}{ Human Capital Model } & \multicolumn{3}{|c|}{ RBC Model } \\
\hline & & $A$ & & & $B$ & & & $A+B$ & & & $A$ & \\
\hline Horizon & $25 \%$ & median & $75 \%$ & $25 \%$ & median & $75 \%$ & $25 \%$ & median & $75 \%$ & $25 \%$ & median & $75 \%$ \\
\hline 1 & 0.0301 & 0.0404 & 0.0523 & 0.0816 & 0.1041 & 0.1290 & 0.1125 & 0.1452 & 0.1815 & 0.0175 & 0.0232 & 0.0317 \\
\hline 4 & 0.0212 & 0.0281 & 0.0361 & 0.0595 & 0.0769 & 0.0964 & 0.0813 & 0.1055 & 0.1329 & 0.0156 & 0.0205 & 0.0276 \\
\hline 8 & 0.0159 & 0.0214 & 0.0279 & 0.0474 & 0.0627 & 0.0811 & 0.0636 & 0.0844 & 0.1094 & 0.0137 & 0.0179 & 0.0240 \\
\hline 12 & 0.0135 & 0.0185 & 0.0245 & 0.0422 & 0.0574 & 0.0753 & 0.0558 & 0.0761 & 0.0999 & 0.0122 & 0.0158 & 0.0213 \\
\hline 20 & 0.0106 & 0.0147 & 0.0199 & 0.0356 & 0.0495 & 0.0659 & 0.0462 & 0.0647 & 0.0860 & 0.0097 & 0.0127 & 0.0169 \\
\hline 40 & 0.0068 & 0.0099 & 0.0138 & 0.0244 & 0.0349 & 0.0483 & 0.0314 & 0.0449 & 0.0623 & 0.0061 & 0.0081 & 0.0106 \\
\hline$\infty$ & 0.0041 & 0.0062 & 0.0090 & 0.0148 & 0.0217 & 0.0312 & 0.0189 & 0.0280 & 0.0403 & 0.0003 & 0.0004 & 0.0005 \\
\hline
\end{tabular}




\section{Conclusions}

This paper has attempted to contribute to both the methods of analysis and the ongoing debate regarding the effects of innovations to productivity on macroeconomic activity. To this end we employed a sectoral decomposition of productivity shocks using an endogenous growth $\mathrm{HC}$ model and an exogenous growth RBC model augmented by VECM measurement errors to explain the dynamics and the trends in the data not captured by the structural models.

We first find, when accounting for aggregate fluctuations in output, consumption, investment and hours, that the combined explanatory power of the TFP and HCP shocks in the human capital (HC) model is generally much larger than innovations to TFP in the RBC model. Second, the HC model significantly improves on the RBC model's ability to explain investment fluctuations, especially in the short-run. Third, while there is still ample room for improvement, the $\mathrm{HC}$ model does significantly better at explaining hours variations than the RBC model. Finally, except for hours worked, TFP shocks in the $\mathrm{HC}$ model explain a relatively larger proportion of the cyclical fluctuations in these aggregates.

Our results for the endogenous growth model are encouraging and suggest that its explanatory power might be further improved by adding more cyclical structure which directly links human capital accumulation with the goods producing sector. For example, in addition to the input of learning time, it is also necessary to employ goods and services such as tools, computers, tuition fees, etc. to acquire human capital. ${ }^{30}$

In light of our finding, we conclude that there is indeed value-added in estimating endogenous models in a hybrid framework which allows both the theory and the data to speak.

\section{References}

Aghion, P. and P. Howitt, 1998, Endogenous Growth Theory (MIT Press, Cambridge and London).

Barro, R., 2001, Human capital and growth, American Economic Review 91, $12-17$.

Barro, R. J., 1991, Economic growth in a cross section of countries, Quarterly Journal of Economics 106, 407-443.

\footnotetext{
${ }^{30}$ For examples of studies employing a human capital specification along these lines, see Jones et al. (1997) and Trostel (1993).
} 
Barro, R. J. and X. Sala-i-Martin, 2004, Economic Growth (MIT Press, Cambridge).

Bauwens, L. and M. Lubrano, 1996, Identification restrictions and posterior densities in cointegrated Gaussian VAR systems, in: T. B. Fomby and R. C. Hill, eds., Advances in Econometrics (JAI Press, Greenwich), vol. 11, 3-28.

Bauwens, L., M. Lubrano, and J.-F. Richard, 1999, Bayesian Inference in Dynamic Econometric Models (Oxford University Press, Oxford).

Benhabib, J. and R. Perli, 1994, Uniqueness and indeterminacy: On the dynamics of endogenous growth, Journal of Economic Theory 63, 113-142.

Benhabib, J. and M. M. Spiegel, 1994, The role of human capital in economic development. evidence from aggregate cross-country data, Journal of Monetary Economics 34, 143-173.

Bils, M. and P. Klenow, 2000, Does schooling cause growth?, American Economic Review 90, 1160-1183.

Černý, V., 1985, Thermodynamical approach to the traveling salesman problem: An efficient simulation algorithm, Journal of Optimization Theory and Applications 45, 41-51.

Chib, S. and E. Greenberg, 1994, Bayes inference in regression models with $\operatorname{ARMA}(\mathrm{p}, \mathrm{q})$ errors, Journal of Econometrics 64, 183-206.

-, 1995, Understanding the Metropolis-Hastings algorithm, American Statistician 49, 327-335.

Chib, S. and S. Ramamurthy, 2010, Tailored randomized-block MCMC methods for analysis of DSGE models, Journal of Econometrics 155, 19-38, forthcoming.

de la Fuente, A. and R. Domenech, 2006, Human capital in growth regressions: How much difference does data quality make?, Journal of the European Economic Association 4, 1-36.

DeJong, D. and B. Ingram, 2001, The cyclical behavior of skill acquisition, Review of Economic Dynamics 4, 536-561.

DeJong, D., B. Ingram, and C. Whiteman, 2000a, A Bayesian approach to dynamic macroeconomics, Journal of Econometrics 98, 203-223. 
—, 2000b, Keynesian impulses versus solow residuals: Identifying sources of business cycle fluctuations, Journal of Applied Econometrics 15, 311-329.

DeJong, D. N., 1992, Co-integration and trend-stationarity in macroeconomic time series : Evidence from the likelihood function, Journal of Econometrics 52, 347-370.

Geweke, J., 1992, Evaluating the accuracy of sampling-based aproaches to the calculation of posterior moments, in: J. Bernardo, J. Berger, A. P. Dawid, and A. F. M. Smith, eds., Bayesian Statistics (Oxford University Press, Oxford), 641-649.

—, 1996, Bayesian reduced rank regression in econometrics, Journal of Econometrics $75,121-146$.

Gill, P. E. and W. Murray, 1974, Newton-type methods for unconstrained and linearly constrained optimization, Mathematical Programming 7, 311-350.

Ireland, P., 2001, Technology shocks and the business cycle: An empirical investigation, Journal of Economic Dynamics and Control 25, 703-719.

- 2004, A method of taking the model to the data, Journal of Economic Dynamics \& Control 28, 1205-1226.

Ireland, P. and S. Schuh, 2008, Productivity and U.S. macroeconomic performance: Interpreting the past and predicting the future with a two-sector real business cycle model, Review of Economic Dynamics 11, 473-492.

Jones, L., R. Manuelli, and P. Rossi, 1997, On the optimal taxation of capital income, Journal of Economic Theory 73, 93-117.

Jones, L., R. Manuelli, and H. Siu, 2005, Fluctuations in convex models of endogenous growth, II: Business cycle properties, Review of Economic Dynamics 8, 805-828.

Jorgenson, D. and B. M. Fraumeni, 1989, The accumulation of human and nonhuman capital, 1948-1984, in: R. E. Lipsey and H. S. Tice, eds., The Measurement of Saving, Investment and Wealth (University of Chicago Press, Chicago), vol. 52 of Studies in Income and Wealth.

Kass, R. E. and A. E. Raftery, 1995, Bayes factors, Journal of the American Statistical Association 90, 773-795. 
King, R. and S. Rebelo, 1999, Resuscitating real business cycles, in: J. Taylor and M. Woodford, eds., Handbook of Macroeconomics (Elsevier, Amsterdam), vol. 1 .

Kirkpatrick, S., C. D. Gelatt, and M. P. Vecchi, 1983, Optimization by simulated annealing, Science 220, 671-680.

Kleibergen, F. and H. K. van Dijk, 1998, Bayesian simultaneous equations analysis using reduced rank structures, Econometric Theory 14, 701-743.

Klein, P., 2000, Using the generalized Schur form to solve a multivariate linear rational expectations model, Journal of Economic Dynamics and Control 24, 1405-1423.

Klenow, P. and A. Rodríguez-Clare, 2005, Externalities and growth, in: P. Aghion and S. Durlauf, eds., Handbook of Economic Growth (Elsevier), vol. 1, 817-861.

Kydland, F. E. and E. C. Prescott, 1982, Time to build and aggregate fluctuations, Econometrica 50, 1345-1370.

Lubrano, M., 1995, Testing for unit roots in a bayesian framework, Journal of Econometrics 69, 81-109.

Lucas, R. E., 1988, On the mechanics of economic development, Journal of Monetary Economics 22, 3-42.

Malley, J. and U. Woitek, 2010, Technology shocks and aggegate fluctuations in an estimated hybrid RBC model, Journal of Economic Dynamics and Control 34, 1214-1232.

Mankiw, N. G., D. Romer, and D. N. Weil, 1992, A contribution to the empirics of economic growth, Quarterly Journal of Economics 107, 407437.

Metropolis, N., A. W. Rosenbluth, M. N. Rosenbluth, A. H. Teller, and E. Teller, 1953, Equations of state calculations by fast computing machines, Journal of Chemical Physics 21, 1087-1092.

Newton, M. A. and A. E. Raftery, 1994, Approximate Bayesian inference with the weighted likelihood bootstrap, Journal of the Royal Statistical Society, Series B 56, 3-48.

Perli, R. and P. Sakellaris, 1998, Human capital formation and business cycle persistence, Journal of Monetary Economics 42, 67-92. 
Press, W. H., S. A. Teukolsky, W. T. Vetterling, and B. P. Flannery, 1992, Numerical Recipes in C. The Art of Scientific Computing (Cambridge University Press, Cambridge), 2nd edn.

Rebelo, S., 2005, Real business cycle models: Past, present and future, Scandinavian Journal of Economics 107, 217-238.

Romer, P. M., 1986, Increasing returns and long-run growth, Journal of Political Economy 94, 1002-1037.

Ruge-Murcia, F., 2007, Methods to estimate dynamic stochastic general equilibrium models, Journal of Economic Dynamics and Control 31, 2599-2636.

Tamura, R., 1991, Income convergence in an endogenous growth model, Journal of Political Economy 99, 522-540.

Temple, J., 2001, Generalizations that aren't? Evidence on education and growth, European Economic Review 45, 905-918.

Trostel, P. A., 1993, The effect of taxation on human capital, Journal of Political Economy 101, 327-350.

van Laarhoven, P. J. M. and E. H. L. Aarts, 1987, Simulated Annealing: Theory and Applications (Kluwer Academic Publishers, Amsterdam). 


\section{Appendices}

\subsection{Stationary DCE relative to $\bar{H}_{t}$}

$$
\begin{gathered}
y_{t}=A_{t}\left(k_{t}\right)^{\alpha}\left(u_{t}\right)^{(1-\alpha)} \\
n \gamma_{t}^{h} k_{t+1}-\left(1-\delta^{k}\right) k_{t}+c_{t}=y_{t} \\
n \gamma_{t}^{h}=1-\delta^{h}+B_{t} e_{t} \\
\lambda_{t}^{a}=\mu\left(c_{t}\right)^{\mu(1-\sigma)-1}\left(1-u_{t}-e_{t}\right)^{(1-\mu)(1-\sigma)} \\
\lambda_{t}^{a}=\beta\left(\gamma_{t}^{h}\right)^{\mu(1-\sigma)-1} E_{t}\left\{\lambda_{t+1}^{a}\left[\frac{\alpha y_{t+1}}{k_{t+1}}+1-\delta^{k}\right]\right\} \\
\lambda_{t}^{a}=\frac{(1-\mu) u_{t}\left(c_{t}\right)^{\mu(1-\sigma)}\left(1-u_{t}-e_{t}\right)^{(1-\mu)(1-\sigma)-1}}{(1-\alpha) y_{t}} \\
\lambda_{t}^{b}=\frac{\mu\left(c_{t}\right)^{\mu(1-\sigma)-1}\left(1-u_{t}-e_{t}\right)^{(1-\mu)(1-\sigma)}(1-\alpha) y_{t}}{B_{t} u_{t}} \\
\lambda_{t}^{b}=\beta\left(\gamma_{t}^{h}\right)^{\mu(1-\sigma)-1} E_{t}\left\{\lambda_{t+1}^{a}(1-\alpha) y_{t+1}+\lambda_{t+1}^{b}\left(1-\delta^{h}+e_{t+1} B_{t+1}\right)\right\}
\end{gathered}
$$

where $\lambda_{t}^{a}$ and $\lambda_{t}^{b}$ are the transformed shadow prices associated with (4) and (6) respectively in the household's problem. ${ }^{31}$

\subsection{Capital stock data}

The capital stock data used in the estimation are from the BEA Fixed Asset Tables 1.1, 1.2. 7.1(a,b) and 7.2(a,b).

\subsubsection{Nominal capital stock}

- We concentrate on the definition of capital which directly contributes to producing measured GDP. Thus starting with Fixed Asset Table 1.1 (nominal billions of $\$$, year end estimates) we proceed as follows:

\begin{tabular}{ll}
\hline Table 1.1 line 3: & private fixed assets (excluding consumer durables) \\
+Table 1.1 line 21: & government fixed assets (state and local) \\
+Table 7.1a line 30: & non-defense fixed assets (federal) \\
+Table 7.1b line 32: & non-defense fixed assets (federal) \\
-Table 1.1 line 7: & private residential fixed assets \\
equals: & nominal capital stock used to produce GDP \\
\hline
\end{tabular}

\footnotetext{
${ }^{31}$ Note that $\lambda_{t}^{a}=\Lambda_{t}^{a} / \bar{H}_{t}^{\mu(1-\sigma)-1}$ and $\lambda_{t}^{b}=\Lambda_{t}^{b} / \bar{H}_{t}^{\mu(1-\sigma)-1}$ where $h$-superscripts have been omitted since we are in a symmetric equilibrium.
} 


\subsubsection{Real capital stock}

- Our estimates of the real capital stock are derived from Tables 1.2 and 7.2. Real stocks are not reported but instead quantity indexes are quoted. We convert each of the nominal measures to real stocks in constant $\$ 2000$ by multiplying the quantity indexes by the nominal value of each of the stocks in 2000 and then dividing by 100 .

\subsubsection{Temporal disaggregation of the capital stock}

- Since this data is not available quarterly we employ the method by Litterman (1983) to distribute the annual series to the quarterly frequency. The quarterly indicator variable we employ to this end is real (billions of chained \$2005) private nonresidential fixed investment, from the BEA.

\subsection{Stationary DCE relative to $\bar{K}_{t}$}

As discussed in the text, the theory consistent stationary DCE can also be obtained by defining any per capita non-stationary variable, $\bar{X}_{t}$, as a share of the observed per capita capital stock, $\bar{K}_{t}$ instead of $\bar{H}_{t}$. Also recall that the log-deviation of any stationary variable from its steady-state is defined as $\widehat{x}_{t}=\ln \left(\frac{x_{t}}{x}\right)$ or in this context $\widehat{x}_{t}=\ln \left(\frac{\bar{X}_{t}}{\bar{K}_{t}}\right)-\ln \left(\frac{\bar{X}}{\bar{K}}\right)$. Hence we can re-express the stationary DCE given by (21) relative to $\bar{K}_{t}$ as follows:

$$
\begin{gathered}
y_{t}=A_{t}\left(u_{t} h_{t}\right)^{(1-\alpha)} \\
n \gamma_{t}^{k}-1+\delta^{k}+c_{t}=y_{t} \\
n \gamma_{t}^{k} h_{t+1}=\left[1-\delta^{h}+B_{t}\left(e_{t}\right)^{\theta}\right] h_{t} \\
\lambda_{t}^{a}=\mu\left(c_{t}\right)^{\mu(1-\sigma)-1}\left(1-u_{t}-e_{t}\right)^{(1-\mu)(1-\sigma)} \\
\lambda_{t}^{a}=\beta\left(\gamma_{t}^{k}\right)^{\mu(1-\sigma)-1} E_{t}\left\{\lambda_{t+1}^{a}\left[\alpha y_{t+1}+1-\delta^{k}\right]\right\} \\
\lambda_{t}^{a}=\frac{(1-\mu) u_{t}\left(c_{t}\right)^{\mu(1-\sigma)}\left(1-u_{t}-e_{t}\right)^{(1-\mu)(1-\sigma)-1}}{(1-\alpha) y_{t}} \\
\lambda_{t}^{b}=\frac{\mu\left(c_{t}\right)^{\mu(1-\sigma)-1}\left(1-u_{t}-e_{t}\right)^{(1-\mu)(1-\sigma)}(1-\alpha) \frac{y_{t}}{h_{t}}}{\theta\left(e_{t}\right)^{\theta-1} B_{t} u_{t}} \\
\lambda_{t}^{b}=\left(\gamma_{t}^{k}\right)^{\mu(1-\sigma)-1} \beta E_{t}\left\{\lambda_{t+1}^{a}(1-\alpha) \frac{y_{t+1}}{h_{t+1}}+\lambda_{t+1}^{b}\left(1-\delta^{h}+\theta\left(e_{t+1}\right)^{\theta} B_{t+1}\right)\right\}
\end{gathered}
$$

where $\gamma_{t}^{k} \equiv \bar{K}_{t+1} / \bar{K}_{t}$. 


\subsection{Recovering the stationary DCE relative to $\bar{H}_{t}$}

To facilitate the comparisons of the impulse response functions and forecast error variance decompositions between the $\mathrm{HC}$ and $\mathrm{RBC}$ models, we need to recover the relevant quantities relative to $\bar{H}_{t}$ post estimation for the $\mathrm{HC}$ model. To this end we apply the following transformations:

$$
\begin{gathered}
\widehat{k}_{t}^{h}=-\widehat{h}_{t}^{k} \\
\widehat{y}_{t}^{h}=\widehat{y}_{t}^{k}-\widehat{h}_{t}^{k} \\
\widehat{c}_{t}^{h}=\widehat{c}_{t}^{k}-\widehat{h}_{t}^{k} \\
\widehat{i}_{t}^{h}=\left(\frac{y}{i}\right) \widehat{y}_{t}^{k}-\left(\frac{c}{i}\right) \widehat{c}_{t}^{k}-\widehat{h}_{t}^{k} \\
\hat{\gamma}_{t}^{h}=\frac{b e^{\theta}}{n \gamma} \hat{b}_{t}^{k}+\frac{b \theta e^{\theta}}{n \gamma} \hat{e}_{t}^{k} \\
\widehat{k}_{t}^{h}=\widehat{h}_{t}^{k}
\end{gathered}
$$

where the $h$ and $k$ superscripts have been added to denote the two representations of the model based on $\bar{H}_{t}$ and $\bar{K}_{t}$ normalizations respectively. 